\title{
DESEMPENHO EM CONSCIÊNCIA SILÁBICA E FONÊMICA EM CRIANÇAS COM DESENVOLVIMENTO DE FALA NORMAL E DESVIANTE
}

\author{
Performance in syllabic and phonemic awareness in children \\ with normal and disordered speech development
}

\author{
Paula Tavares Marchetti ${ }^{(1)}$, Carolina Lisbôa Mezzomo (2), Carla Aparecida Cielo ${ }^{(3)}$
}

\begin{abstract}
RESUMO
Objetivo: comparar o desempenho nas habilidades metafonológicas, no nível silábico e fonêmico, por meio do Protocolo de Tarefas de Consciência Fonológica (Cielo, 2001) entre crianças com desenvolvimento de fala normal e desviante (DFE), com idades entre 4 e 8 anos. Métodos: participaram da pesquisa 49 sujeitos, 26 do GR (grupo de referência) sem DFE, os quais fizeram parte da pesquisa de Cielo (2001) e 23 do GE (grupo de estudo) com DFE. Todos os sujeitos foram submetidos à avaliação fonoaudiológica e da consciência fonológica (CF). Resultados: dos 12 subtestes, envolvendo consciência silábica, em seis $(50 \%)$ houve diferença estatisticamente significante entre o GE e o GR, confirmando o pior desempenho do GE. Nos 10 subtestes envolvendo as tarefas de consciência fonêmica, em seis (60\%) apresentaram diferenças estatisticamente significante. Porém, na análise das médias de acertos observou-se a tendência do pior desempenho do GE em comparação ao GR, $\mathrm{em}$ todas as tarefas. Existe uma diferença estatisticamente significante no desempenho de tarefas de CF (segmentação silábica em dissílabas, trissílabas e quadrissílabas; detecção silábica inicial e final; reversão silábica em dissílabas; detecção de fonemas inicial e final; síntese fonêmica com 3, 4, 5 e 6 fonemas) entre crianças com desenvolvimento de fala normal e crianças com DFE. Conclusões: na análise geral dos dados as crianças com DFE obtiveram pior desempenho nas tarefas de CF do que as crianças com desenvolvimento de fala normal. Somado ao pior desempenho, as crianças do GE também não conseguiram realizar as tarefas de reversão e segmentação fonêmica.
\end{abstract}

DESCRITORES: Conscientização; Distúrbios da Fala; Fala; Percepção da Fala

\section{INTRODUÇÃO}

Crianças com aproximadamente quatro anos de idade e desenvolvimento normal de fala fazem uso

(1) Fonoaudióloga; Audioclínica OuveBem, Santa Maria, RS; Mestranda do Programa de Pós-Graduação em Distúrbios da Comunicação Humana da Universidade Federal de Santa Maria.

(2) Fonoaudióloga; Professora Adjunto do Departamento de Oftalmologia e Otorrinolaringologia da Fundação Universidade Federal de Ciências da Saúde de Porto Alegre, UFCSPA, Porto Alegre, RS; Doutora em Letras pela Pontifícia Universidade Católica do Rio Grande do Sul.

(3) Fonoaudióloga; Professora Adjunto do Departamento de Fonoaudiologia; Professora do Programa de Pós-Graduação em Distúrbios da Comunicação Humana da Universidade Federal de Santa Maria, UFSM, Santa Maria, RS; Doutora em Letras pela Pontifícia Universidade Católica do Rio Grande do Sul.

Conflito de interesses: inexistente adequado da fonologia de sua língua, empregando os contrastes fonêmicos de maneira satisfatória. Em contraste, se nesta mesma idade as dificuldades na organização dos sons da fala persistirem, na ausência de um acometimento orgânico, se está diante de uma fala desviante ou de um desvio fonológico evolutivo (DFE) ${ }^{1-7}$.

O uso do termo DFE indica que se trata de um desvio, um afastamento de uma linha de normalidade, que ocorre no componente fonológico da língua, no desenvolvimento linguístico da criança. A fala com desvios representa um sistema fonológico consistente e organizado, mesmo que apresente diferenças do sistema padrão bem como promova dificuldades de inteligibilidade em maior ou menor grau $^{1,3-6}$. O conceito de DFE faz parte da premissa de que a fala com desvios constitui um sistema fonológico. Nessa fala, nada é aleatório ou casual, 
pois existe um sistema consistente, de regras que, num primeiro momento, pode não estar claro ou observado em razão do afastamento daquele que é esperado ${ }^{1,3-6}$.

Outro conceito de DFE postula que este acometimento é uma desordem linguística que se manifesta pelo uso de padrões anormais no meio falado da linguagem. Esta definição enfatiza que o transtorno afeta o nível fonológico da organização linguística e não a mecânica da produção articulatória ${ }^{8}$.

O domínio da fonologia não é suficiente no processo de aquisição da leitura e da escrita, este domínio seria a base para a generalização do sistema alfabético juntamente com a consciência fonêmica. Assim, as dificuldades com a fala podem interferir no desempenho escolar posterior de crianças que tenham DFE. Tais dificuldades podem residir no desenvolvimento da consciência fonológica (CF) ou na aquisição das habilidades de leitura e de escrita. Devido a estas dificuldades, a criança pode ser sobrecarregada no ambiente escolar ${ }^{4,6,9-16}$.

A CF é a habilidade que permite à criança pensar sobre as palavras e perceber que as mesmas podem ser formadas por componentes menores e que estes podem ser combinados de várias maneiras. É a habilidade de analisar a fala explicitamente em seus componentes fonológicos 2,9-12,17-19.

As tarefas de CF avaliam as habilidades metafonológicas no nível das frases, das palavras, das sílabas e dos fonemas. Geralmente, tarefas de segmentação de frases, detecção de rimas, realismo nominal, tarefas silábicas e fonêmicas são utilizadas nos protocolos existentes.

As duas últimas tarefas citadas terão enfoque na presente pesquisa devido ao fato de se supor que elas tenham mais relação com o nível fonológico, justamente o aspecto formal da língua que estaria afetado nas crianças com DFE 7,13,14,19-21. A tarefa de síntese silábica verifica a habilidade da criança de realizar auditivamente a junção de sílabas isoladas para formar palavras. A segmentação silábica objetiva avaliar a habilidade de separar as unidades silábicas das palavras. A atividade de detecção de sílabas tem a finalidade de verificar a habilidade de perceber e localizar sílabas dentro de palavras apresentadas oralmente. A tarefa de reversão silábica tem como objetivo verificar a habilidade de segmentar, manipular e juntar sílabas de palavras apresentadas oralmente ${ }^{17}$.

Por sua vez, a atividade de exclusão fonêmica objetiva avaliar a habilidade do sujeito de excluir um fonema de determinadas palavras, formando novas palavras. A tarefa de detecção de fonemas tem a finalidade de analisar a habilidade da criança de perceber e localizar fonemas em palavras orais. A tarefa de síntese fonêmica avalia a habilidade de juntar fonemas isolados apresentados oralmente para formar palavras. A tarefa de segmentação fonêmica é semelhante à anterior, porém em fala normal, sem segmentação. A finalidade da tarefa de reversão fonêmica é avaliar a habilidade da criança de segmentar palavras em fonemas, de manipular e juntar fonemas de palavras apresentadas oralmente, além de sua habilidade de modificar os valores fonético-fonológicos dos fonemas com base no domínio do código alfabético ${ }^{17}$.

A CF depende de um sistema de processamento intacto, isto é, as crianças conseguem "entrar" no estágio metafonológico quando conseguem aplicar o que conquistaram nos estágios anteriores de estocagem e produção de linguagem e fala. Logo, crianças que têm habilidades metafonológicas bem desenvolvidas, irão aprender a leitura e escrita de forma mais eficiente ${ }^{9,10,13,14,16,21-23}$.

Como a CF diz respeito à utilização da informação fonológica para o processamento da linguagem oral e escrita, há um grande risco de crianças com DFE apresentarem problemas de CF e, como consequência, dificuldades na alfabetização ${ }^{6,9,11,13,16,24-26 . ~}$

Estudos têm mostrado que crianças com DFE são de alto risco para iniciar o ensino formal com déficits na CF. Apesar do esforço, estas crianças apresentam dificuldades na aprendizagem, mostrando baixo desempenho nas tarefas de leitura e escrita, soletração e leitura fonética ${ }^{16,22}$.

Além disso, pesquisadores que compararam crianças com desenvolvimento de fala normal e crianças com DFE, perceberam que as últimas têm desempenho inferior nas habilidades metafonológicas ${ }^{6,21,27-29}$. Porém, alguns autores pesquisaram a relação entre CF e DFE, e verificaram que muitas crianças com DFE apresentavam um conhecimento fonológico melhor do que eram capazes de produzir oralmente ${ }^{2,4}$.

Desse modo, a identificação e o tratamento das dificuldades em CF são pontos importantes da prática clínica fonoaudiológica, sobretudo porque há ligação direta entre o desenvolvimento da CF e a aquisição da leitura e da escrita 9,10,15,17,18,25,30,31.

Neste contexto, o presente trabalho teve como objetivo comparar o desempenho nas habilidades metafonológicas, no nível da consciência silábica e fonêmica, entre crianças com desenvolvimento de fala normal e crianças com DFE, com idades entre quatro e oito anos.

\section{MÉTODOS}

A presente pesquisa é um estudo exploratório, experimental, de caráter quantitativo. A amostra estudada foi dividida em dois grupos: grupo de 
estudo (GE - com desvio fonológico) e um grupo de referência (GR - sem desvio fonológico).

O GR foi composto pelos sujeitos da pesquisa de Cielo ${ }^{17}$, escolhidos de modo aleatório entre os 85 indivíduos que compuseram o GE da autora. $\mathrm{Na}$ pesquisa referida, todas as crianças apresentavam desenvolvimento fonológico normal, tinham idades entre quatro e oito anos e foram investigadas sobre suas habilidades em CF. Os sujeitos do GR foram selecionados até atingir um número aproximado ao número de sujeitos do GE.

Os sujeitos do grupo de estudo (GE) foram selecionados no Serviço de Atendimento Fonoaudiológico (SAF) da instituição de origem, a partir da análise de todos os pacientes atendidos no setor de fala e no setor de triagem fonoaudiológica. Os candidatos do GE a participar desta pesquisa foram somente aqueles pacientes que receberam diagnóstico de DFE de acordo com a literatura ${ }^{8}$, que iniciaram atendimento fonoaudiológico no ano de 2006 ou que estivessem na lista de espera para atendimento no setor de fala. Além disso, as crianças deveriam apresentar idades entre quatro a oito anos, e deveriam estar frequentando o jardim de infância, a pré-escola, a $1^{\text {a }}$ série ou a $2^{2}$ série do ensino fundamental.

Além dos aspectos mencionados acima, os critérios de exclusão do GE foram: os sujeitos que apresentassem alterações evidentes nos aspectos neurológico, cognitivo, psicológico e/ou emocional, bem como alterações audiológicas.

Para observar tais aspectos, os pacientes que fariam parte do GE foram submetidos a avaliações fonoaudiológicas e complementares. As avaliações complementares consistiram de: avaliações audiológica, neurológica e otorrinolaringológica.

As avaliações fonoaudiológicas aplicadas foram: avaliações do sistema estomatognático e avaliação da fala, para as quais foram utilizados os protocolos do Serviço de Atendimento Fonoaudiológico da instituição de origem. Tais avaliações foram realizadas pelas respectivas terapeutas (alunas do $7^{\circ}$ semestre do curso de fonoaudiologia, em estágio supervisionado) de cada criança que já estava em atendimento no setor de fala. Essas terapeutas também realizaram as mesmas avaliações no setor de triagem nas crianças que estavam na lista de espera, com exceção da Avaliação Fonológica da Criança que foi realizada por uma das autoras.

$\mathrm{Na}$ avaliação do sistema estomatognático, foram observados aspectos relacionados à estrutura dos órgãos fonoarticulatórios (lábios, língua, bochechas, palato mole, palato duro, mandíbula e arcada dentária), tais como morfologia, postura, tônus e mobilidade, bem como aspectos relacionados às funções estomatognáticas. Essa avaliação foi realizada a fim de descartar a existência de fatores orgânicos que pudessem estar interferindo na produção correta dos sons, o que causaria a alteração da fala observada.

Também foi realizada a Avaliação Fonológica da Criança ${ }^{32}$, a qual consistiu da coleta de uma amostra de fala por meio da nomeação espontânea, realizada com a utilização do instrumento composto de cinco figuras temáticas (banheiro, cozinha, sala, veículos, e zoológico). Esta avaliação possibilitou a elicitação de todos os fonemas contrastivos do português brasileiro em todas as posições silábicas.

Os dados foram gravados em formato digital, em mp3 player modelo $1 \mathrm{G}$ da marca Sony, e gravador analógico com fita cassete modelo RQ-L10 da Panasonic, ambos com qualidade de gravação suficiente para a análise perceptual. Após a coleta, os dados foram submetidos à transcrição fonética restrita e à análise contrastiva. A análise contrastiva foi realizada com o objetivo de comparar o sistema da criança com o sistema padrão do adulto, estabelecendo-se o inventário fonológico desviante de cada criança.

O total da amostra totalizou 49 sujeitos. A partir dos critérios de inclusão e exclusão no GE, formouse um grupo de 23 sujeitos. O GR ficou formado por 26 sujeitos.

A avaliação da CF foi realizada no GE seguindo o Protocolo de Tarefas de Consciência Fonológica ${ }^{17}$. Tal avaliação da CF foi aplicada por uma das autoras, fonoaudióloga graduada e com especialização em Fonoaudiologia, em todas as crianças da GE.

Essa avaliação possibilita analisar as habilidades metafonológicas em: segmentação de frases em palavras; realismo nominal; detecção de rimas; síntese silábica; segmentação silábica; detecção de sílabas; reversão silábica; exclusão fonêmica; detecção de fonemas; síntese fonêmica; segmentação fonêmica e reversão fonêmica. Porém, para este trabalho, foram aplicadas e analisadas somente as tarefas no nível de sílabas e de fonemas. Optou-se por analisar as tarefas silábicas e fonêmicas uma vez que estas habilidades têm mais relação com o nível fonológico, justamente o aspecto formal da língua que estaria afetado nas crianças com DFE.

Participaram da pesquisa somente aqueles sujeitos que após serem informados sobre os objetivos, os procedimentos a serem adotados, os riscos e os benefícios do presente estudo, assinaram o Termo de Consentimento Livre e Esclarecido.

Em relação à aplicação do Protocolo de Tarefas de Consciência Fonológica ${ }^{17,18}$, para cada resposta correta na primeira tentativa foi atribuído o valor 2; para cada resposta correta na segunda tentativa foi atribuído o valor 1; e para as respostas incorretas foi atribuído o valor 0 (zero). 
O máximo de acertos possíveis em cada subtarefa é 10 (dez) e o critério de êxito individual é de, no mínimo, $50 \%$ de acertos ${ }^{17,18}$.

Esta pesquisa faz parte do projeto "Comparação da performance nas tarefas de consciência silábica e fonêmica entre crianças com desenvolvimento fonológico normal e desviante", o qual foi aprovado pelo Comitê de Ética em Pesquisa (CEP) da Universidade Federal de Santa Maria (UFSM), cujo número de processo é 23081.007155/2006-13.

Após a coleta dos dados e o levantamento dos dados de normalidade, segundo a literatura ${ }^{17}$, os dados foram analisados estatisticamente por meio do Teste não-paramétrico de Kruskal-Wallis. O nível de significância utilizado foi de $5 \%$.

\section{RESULTADOS}

Os resultados desta pesquisa foram divididos em tabelas, de acordo com o desempenho atingido pelos diferentes grupos estudados (GR e GE) no teste de CF.

Observa-se que houve diferença estatisticamente significante nos testes de segmentação silábica (T5), detecção silábica (T6), reversão silábica (T7), detecção fonêmica (T9) e síntese fonêmica (T10).

No entanto, como se pode observar, não houve resultados estatisticamente significantes para nenhuma das subtarefas dos testes de síntese silábica (T4) e exclusão fonêmica (T8). Porém, nota-se pelas médias que existe uma tendência de os sujeitos com DFE terem desempenho inferior nessas tarefas.

Naquelas subtarefas cujo resultado não foi estatisticamente significante (T6 medial; T7 em trissílabas e quadrissílabas; T9 medial), observa-se uma tendência de as crianças com fala desviante terem resultados inferiores às crianças com desenvolvimento fonológico normal.

Por fim, as tarefas de segmentação fonêmica (T11) e reversão fonêmica (T12) não foram realizadas por nenhuma das crianças com DFE. Os subtestes referidos não foram feitos por não serem coerentes com a idade da maioria das crianças testadas, ao passo que aquelas que tinham a idade necessária, não conseguiram realizar as tarefas. Além disso, as crianças com desenvolvimento de fala normal também mostram dificuldades com essas tarefas.

$\mathrm{Na}$ Tabela 1, pode-se observar que no teste de síntese silábica (T4) os sujeitos da pesquisa não mostraram dificuldades. Esta afirmação se baseia nas médias de acerto de ambos os grupos.

Já para o teste de segmentação silábica (T5), observa-se, que houve diferença significante entre os grupos (GR e GE) em todos sub-testes. O GR apresentou médias superiores, não mostrando dificuldades com a tarefa de segmentação silábica.

Quanto ao teste de detecção silábica (T6), evidenciou-se que ambos os grupos apresentam dificuldades. Porém, no subteste T6 inicial e final, o GE apresentou maior dificuldade, pois houve diferença estatisticamente significante.

Observa-se, na Tabela 1, que os sujeitos do GE tiveram maior dificuldade na tarefa de reversão silábica com dissílabas. Contudo, essa tarefa também apresentou dificuldade para todos os sujeitos da pesquisa, incluindo o GR, visto que as médias de acertos são baixas. Outro dado relevante é que quanto maior o número de sílabas, menor a média de acertos para ambos os grupos.

Nota-se na Tabela 2 que os sujeitos do GE que poderiam realizar a tarefa de exclusão fonêmica mostraram grande dificuldade. Como o número de sujeitos do GE diminui conforme a dificuldade das tarefas, não foi possível observar uma diferença estatisticamente significante. Dificuldades com a tarefa de exclusão fonêmica também são verificadas em crianças com desenvolvimento fonológico normal.

Observa-se que nos subtestes inicial e final da tarefa de detecção fonêmica (T9) houve diferença estatisticamente significante, indicando pior desempenho do GE.

Como se percebe na tarefa de detecção fonêmica, a dificuldade do GE foi mais acentuada principalmente nas subtarefas T9 inicial e final. Essa tarefa parece ser difícil também para o GR na posição medial, pois, comparando-se com as médias de acertos das outras subtarefas para o mesmo grupo, na subtarefa T9 medial a média de acertos foi inferior. Entretanto, qualitativamente as médias do GR foram superiores ao GE.

No teste de síntese fonêmica (T10), é notável a dificuldade do GE uma vez que, de todos os sujeitos do GE que poderiam realizar a tarefa nenhum obteve êxito. $\mathrm{Na}$ análise dessa tarefa, houve diferença estatisticamente significante em todas as subtarefas, confirmando o pior desempenho do GE. As subtarefas T10 (5 fonemas) e T10 (6 fonemas) parecem apresentar certo grau de dificuldade também para os sujeitos do GR. Conforme aumenta o número de fonemas na tarefa, a média de acertos do GR diminui. Porém, qualitativamente, a média de acertos é superior à do GE.

Dos 12 subtestes envolvendo consciência silábica, em seis (50\% das tarefas) houve diferença estatisticamente significante entre o GE e o GR, confirmando o pior desempenho do GE. Nos 10 subtestes envolvendo as tarefas de consciência fonêmica, seis (60\% das tarefas) apresentaram 
Tabela 1 - Resultados das tarefas em consciência silábica para cada subteste **

\begin{tabular}{llllll}
\hline Sub-tarefa & Grupos & $\mathbf{n}$ & Média & D.P & valor de $\mathbf{p}^{*}$ \\
\hline Síntese silábica & GR & 26 & 9.7692308 & 0.5870395 & \\
T4 dissílabas & GE & 23 & 9.5217391 & 1.0387740 & 0.4945 \\
\hline Síntese silábica & GR & 26 & 9.8076923 & 0.6939297 & \\
T4 trissílabas & GE & 23 & 9.5652174 & 1.0368697 & 0.3157 \\
\hline Síntese silábica & GR & 26 & 9.6923077 & 0.9703290 & \\
T4 quadrissílabas & GE & 23 & 9.5652174 & 1.0368697 & 0.5756 \\
\hline Segmentação silábica & GR & 26 & 9.9615385 & 0.1961161 & \\
T5 dissílabas & GE & 23 & 7.7391304 & 2.7504940 & $\mathbf{0 . 0 0 0 1}$ \\
\hline Segmentação silábica & GR & 26 & 9.9615385 & 0.1961161 & \\
T5 trissílabas & GE & 23 & 7.3043478 & 3.4566771 & $\mathbf{0 . 0 0 0 1}$ \\
\hline Segmentação silábica & GR & 26 & 9.9230769 & 0.3922323 & \\
T5 quadrissílabas & GE & 23 & 7.2173913 & 3.6798780 & $\mathbf{0 . 0 0 0 3}$ \\
\hline Detecção silábica & GR & 26 & 7.7307692 & 2.8221650 & \\
T6 inicial & GE & 17 & 5.7058824 & 3.4235345 & $\mathbf{0 . 0 1 6 8}$ \\
\hline Detecção silábica & GR & 26 & 6.6923077 & 2.8812390 & \\
T6 final & GE & 17 & 4.1176471 & 3.3332108 & $\mathbf{0 . 0 1 8 7}$ \\
\hline Detecção silábica & GR & 26 & 6.0769231 & 3.0973934 & \\
T6 medial & GE & 17 & 4.5882353 & 2.8952293 & 0.0910 \\
\hline Reversão silábica & GR & 26 & 5.8846154 & 4.2457218 & \\
T7 dissílabas & GE & 15 & 2.4666667 & 3.4198301 & $\mathbf{0 . 0 2 2 9}$ \\
\hline Reversão silábica & GR & 26 & 4.0000000 & 3.6331804 & \\
T7 trissílabas & GE & 10 & 2.2000000 & 3.1902630 & 0.2396 \\
\hline Reversão silábica & GR & 26 & 3.5000000 & 3.2155870 & \\
T7 quadrissílabas & GE & 10 & 1.6000000 & 2.1186998 & 0.0981 \\
\hline ** Teste Kruskal-Wallis & & & & & \\
* valor de p<0.05 diferença significante & & & & & \\
GR: grupo de referência & & & & & \\
GE: grupo de estudo & & & & & \\
n: número de sujeitos & & & & & \\
D.P: desvio padrão & & & & & \\
& & & & & \\
\end{tabular}

diferenças estatisticamente significantes. Esse fato parece indicar que o prejuízo da criança se concentra tanto no nível segmental quanto no prosódico (sílaba), com predomínio de dificuldades nas tarefas de consciência fonêmica.

\section{DISCUSSÃO}

Comparando-se os resultados obtidos com a bibliografia existente na área, verifica-se que estudos contrastando crianças com desenvolvimento de fala normal e crianças com DFE obtiveram resultados semelhantes aos encontrados no presente trabalho.

Crianças com DFE tendem a apresentar habilidades em CF e em decodificação significativamente inferiores a crianças com desenvolvimento de fala normal, independentemente do grau de severidade do DFE $16,22,23,26,28,29$. Os mesmos resultados foram observados pela presente pesquisa em relação às tarefas de segmentação silábica, detecção silábica (inicial e final), reversão silábica (dissílabas), detecção fonêmica (inicial e final) e síntese fonêmica.

Ao contrário, algumas pesquisas relatam que nem todas as crianças com DFE terão problemas com as habilidades necessárias para aquisição da leitura e escrita, como as habilidades metafonológicas. Segundo esses trabalhos, algumas crianças até estariam mais adiantadas em habilidades mais complexas de CF, em comparação com seus pares sem DFE ${ }^{24,33,34}$.

Crianças com DFE têm maior dificuldade de fazer julgamentos corretos das palavras-alvo se comparadas com crianças que tenham desenvolvimento típico de fala. Observa-se que crianças com DFE são mais suscetíveis a desenvolverem 
Tabela 2 - Resultados das tarefas em consciência fonêmica para cada subteste **

\begin{tabular}{|c|c|c|c|c|c|}
\hline Sub-tarefa & Grupo & $\mathbf{n}$ & Média & D.P & ${ }^{*}$ valor de $p$ \\
\hline Exclusão fonêmica & $\mathrm{GR}$ & 26 & 4.5769231 & 4.6748097 & \\
\hline T8 inicial & GE & 10 & 1.3000000 & 2.3118055 & 0.0675 \\
\hline Exclusão fonêmica & GR & 26 & 5.5000000 & 4.6065171 & \\
\hline T8 final & GE & 10 & 3.0000000 & 4.8304589 & 0.2708 \\
\hline Exclusão fonêmica & $\overline{G R}$ & 26 & 5.1923077 & 4.6905798 & \\
\hline T8 medial & GE & 10 & 2.5000000 & 4.0345728 & 0.0676 \\
\hline Detecção fonêmica & GR & 26 & 7.0384615 & 3.1809529 & \\
\hline T9 inicial & GE & 17 & 3.9411765 & 3.7160225 & 0.0096 \\
\hline Detecção fonêmica & GR & 26 & 5.2692308 & 2.9333625 & \\
\hline T9 final & GE & 13 & 2.6923077 & 2.7502914 & 0.0123 \\
\hline Detecção fonêmica & GR & 26 & 4.6538462 & 3.2977848 & \\
\hline T9 medial & GE & 10 & 3.0000000 & 2.8674418 & 0.1623 \\
\hline Síntese fonêmica & GR & 26 & 4.8846154 & 4.3664807 & \\
\hline T10 - 3 fonemas & GE & 09 & 0.4444444 & 0.8819171 & 0.0141 \\
\hline Síntese fonêmica & GR & 26 & 4.5384615 & 4.4562834 & \\
\hline T10 - 4 fonemas & GE & 09 & 0.2222222 & 0.6666667 & 0.0168 \\
\hline Síntese fonêmica & GR & 26 & 2.8846154 & 3.1790177 & \\
\hline T10 - 5 fonemas & GE & 09 & 0 & 0 & 0.0108 \\
\hline Síntese fonêmica & GR & 26 & 2.8846154 & 3.3861710 & \\
\hline T10 - 6 fonemas & GE & 08 & 0 & 0 & 0.0223 \\
\hline $\begin{array}{l}\text { * Teste Kruskal-Wallis } \\
\text { valor de } p<0,05 \text { diferença } \\
\text { - não obtiveram nenhum } \\
\text { aR: grupo de referência } \\
\text { aE: grupo de estudo } \\
\text { : número de sujeitos } \\
\text {.P: desvio padrão }\end{array}$ & sub-tarefa & & & & \\
\hline
\end{tabular}

dificuldades na formação de novas representações fonológicas, isto é, a refletir deliberadamente sobre suas representações se comparadas com crianças sem DFE. Isso se confirma na comparação entre o GR e o GE desta pesquisa em relação aos resultados das tarefas, pois as médias do GE foram sempre inferiores às do GR. Crianças que não têm acesso a uma representação fonológica precisa farão um esforço considerável para manipular os componentes segmentais das palavras, como exigidos durante tarefas de CF 22,35 .

Crianças com DFE apresentam um escore pior nas tarefas de síntese fonêmica e rimas em relação a crianças sem desvio no nível fonêmico ${ }^{13,19,28,29}$. Além disso, crianças com dificuldade de fala têm dificuldade no aprendizado de palavras que estejam em uma narrativa; isto é, uma dificuldade com segmentação de frases em palavras ${ }^{23}$. No presente estudo, pôde-se observar que os sujeitos com DFE obtiveram desempenho significativamente pior em todas as subtarefas, se comparados aos sujeitos com desenvolvimento de fala normal.
Os resultados obtidos neste estudo também reforçam outra pesquisa que avaliou escolares com DFE, na qual foi concluído que, quanto à habilidade fonêmica verificada na Prova de CF, ocorreu prevalência de erros na habilidade em síntese, segmentação, manipulação e transposição fonêmica. Esse resultado indica que, na população estudada, as dificuldades fonológicas presentes na oralidade influenciaram diretamente as representações mentais em tarefas de fala, leitura e escrita ${ }^{9}$. Na presente pesquisa, os resultados estatisticamente significantes obtidos nas tarefas de síntese, detecção e exclusão fonêmica vão ao encontro da literatura, ao mostrar uma diferença significante ou uma tendência a um pior desempenho pelo GE.

Nas pesquisas citadas, as tarefas fonêmicas foram mais difíceis para as crianças com DFE. Elas tiveram pior desempenho com identificação, segmentação e síntese fonêmica, confirmando os achados desta pesquisa, na qual as crianças com DFE tiveram desempenho significativamente pior nas tarefas de detecção e síntese fonêmica ${ }^{7,14,19,28,29}$. 
A qualidade das representações fonêmicas pode ser refletida na fonologia expressiva das crianças. Estudos envolvendo crianças com DFE têm concluído que crianças com fala desviante apresentam desempenho inferior em tarefas específicas de consciência fonêmica, se comparadas a crianças com padrões fonológicos normais ${ }^{4,7,28,29}$. Do mesmo modo, os dados encontrados neste estudo em relação às tarefas de detecção e síntese fonêmica apresentaram resultados significantemente piores para as crianças com DFE.

De acordo com os achados no presente estudo, a fala tem um papel causal direto no desenvolvimento da consciência fonêmica. Supõe-se que a qualidade ou a força das representações fonêmicas pode determinar a precisão das produções das crianças, as quais, por sua vez, podem retornar sobre as representações das crianças, embora reforçando ou enfraquecendo essas representações ${ }^{13,21}$.

Confirmando os achados deste estudo, nos quais as crianças com DFE tiveram pior desempenho que o GR nas tarefas de CF, é conhecido que crianças com DFE podem ter dificuldades com CF. A compreensão da fonte dessas dificuldades requer entender que outras variáveis podem acometer a emergência da CF entre crianças com desenvolvimento normal e crianças com DFE. Estudos provam que a emergência da $C F$ em crianças com DFE é governada por alguns fatores internos, tais como idade, grau do desvio e processamento fonológico (memória de trabalho, atenção e acesso ao léxico mental); assim como fatores externos, como a estimulação que a criança recebeu no ambiente familiar e escolar para refletir sobre a língua e suas estruturas sonoras ${ }^{4,5,25,31}$. A persistência do DFE no período de idade escolar também pode ser identificada como um fator de risco para problemas com a aquisição da CF e da leitura ${ }^{4,13,15,25,27-29}$. Na presente pesquisa a maioria dos sujeitos em idade escolar com DFE não obteve êxito ou não conseguiram realizar as tarefas no nível do fonema.
Confirmando os resultados de baixo desempenho dos sujeitos com DFE nas tarefas de CF obtidos na presente pesquisa, a literatura da área mostra que o desenvolvimento pobre em CF é evidente para crianças com dificuldade de fala, independentemente do fato de essas crianças terem déficits em outras áreas da linguagem (gramática e vocabulário) ou de elas mostrarem dificuldade de fala isolada ${ }^{24}$.

Crianças com DFE podem ter consciência do sistema fonológico considerada normal, uma vez que todos os sujeitos da presente pesquisa mostraram habilidade de refletir sobre os sons da fonologia do português, respondendo ao teste de $\mathrm{CF}^{2,4}$. A consciência do próprio desvio parece interferir no desempenho de crianças com DFE, funcionando como um facilitador ${ }^{2}$. Tal achado pode justificar o porquê de algumas crianças com DFE da pesquisa não terem desempenho tão baixo nas habilidades metafonológicas, havendo desta forma diferenças estatisticamente significantes a favor do GR somente em oito das vinte e duas subtarefas de CF aplicadas nos grupos estudados.

\section{CONCLUSÃO}

Houve diferença estatisticamente significante no desempenho de tarefas de consciência silábica e fonêmica nas crianças com desenvolvimento de fala normal e com DFE, a favor de crianças com fala normal.

Além disso, as crianças com DFE não conseguiram realizar as tarefas de segmentação e reversão fonêmica, havendo uma tendência de as crianças com fala desviante mostrarem pior desempenho do que as crianças sem DFE nas tarefas de consciência silábica e fonêmica.

Pelos resultados obtidos na presente pesquisa, pôde-se observar que as tarefas fonêmicas foram as mais difíceis para as crianças com DFE, o que aponta para a relação direta entre o desenvolvimento fonológico e a consciência fonêmica. 


\begin{abstract}
Purpose: to compare the performance in the metaphonological skills at the level of syllabic and phonemic awareness, among children with normal development of speech and children with evolutional phonological disorder (EFD), aged 4 and 8 years. Methods: 49 subjects took part in the research, being 26 of the RG (reference group) without EFD, who were part of the research by Cielo (2001), and 23 of the SG (study group) with EFD. All the subjects were submitted to speech and language pathologist evaluation and the assessment of the phonological awareness. Results: from the twelve sub-tests involving syllabic awareness, six (50\%) presented statistically significant difference between the RG and $S G$, confirming the worst performance by the SG. In the ten sub-tests involving the tasks of phonemic awareness, six $(60 \%)$ showed statistically significant differences. However, in the analysis of the averages of the successful results there was a tendency of worse performance by the SG if compared to the RG in all tasks. There is a statistically significant difference in the performance of phonological awareness tasks (syllabic segmentation in two syllables, three syllables and four syllables; initial and final syllables detection; syllabic reversion in two syllables; initial and final phoneme detection; phonemic synthesis with three, four, five and six phonemes) among children with normal development of speech and children with EFD. Conclusion: in data general analysis, children with EFD were worst than children with normal speech development in PA tasks. In addition to the worst performance, the children with SG also failed to perform the phonemic reversion and segmentation tasks.
\end{abstract}

KEYWORDS: Awareness; Speech Disorders; Speech; Speech Perception

\section{REFERÊNCIAS}

1. Lamprecht RR. Desvios fonológicos: evolução nas pesquisas, conhecimento atual e implicações clínicas. In: Aquisição da linguagem: questões e análises. Porto Alegre: Edipucrs; 1999. p.65-80.

2. Menezes G, Lamprecht RR. A consciência fonológica na relação fala-escrita em crianças com desvios fonológicos evolutivos (DFE). Letras de Hoje. 2001; 36(125):743-9.

3. Lamprecht RR. Sobre os desvios fonológicos. In: Lamprecht RR, organizador. Aquisição fonológica do português. Perfil de desenvolvimento e subsídios para terapia. Porto Alegre: Artmed; 2004.p.193212.

4. Vieira M, Mota HB, Keske-Soares M. Relação entre idade, grau de severidade do desvio fonológico e consciência fonológica. Rev Soc Bras Fonoaudiol. 2004; 9(3):144-50.

5. Linassi LZ, Keske-Soares M, MotaHB. Habilidades de memória de trabalho e o grau de severidade do desvio fonológico. Pró-Fono. 2005; 17(3):383-92.

6. Ardenghi LG, Mota HB, Keske-Soares M. A terapia Metaphon em casos de desvios fonológicos. Rev Soc Bras Fonoaudiol. 2006; 11(2):106-15.

7. Spíndola RA, Payão LMC, Bandini HHM. Abordagem fonoaudiológica em desvios fonológicos fundamentada na hierarquia dos traços distintivos e na consciência fonológica. Rev CEFAC. 2007; 9(2):180-9.
8. Grunwell P. Os desvios fonológicos numa perspectiva lingüística. In: Yavas MS. Desvios fonológicos em crianças. Teoria, pesquisa e tratamento. Porto Alegre: Mercado Aberto; 1990. p. 51-82.

9. Salgado C, Capellini SA. Desempenho em leitura e escrita de escolares com transtornos fonológicos. Psicol Escol Educ. 2004; 8(2):179-88.

10. Pestun MSV. Consciência fonológica no início da escolarização e o desempenho ulterior em leitura e escrita: estudo correlacional. Est Psicol. 2005; 10(3):407-12.

11. Avila CRB. Consciência fonológica In: Ferreira LP, Befi-Lopes DM, Limongi SCO. Tratado de fonoaudiologia. São Paulo: Roca; 2004. p. 815-24.

12. Freitas GCMA. Consciência fonológica e aquisição da escrita: um estudo longitudinal. 2004. [tese] Porto Alegre (RS): Pontifica Universidade Católica; 2004.

13. Nathan L, Stackhouse J, Goulandris N, Snowling MJ. The development of early literacy skills among children with speech difficulties: a test of the "critical age hypothesis". J Speech Lang Hear Res. 2004; 47(2):377-91.

14. Sutherland D, Gillon GT. Development of phonological representations and phonological awareness in children with speech impairment. Int J Lang Commun Disord. 2007; 42(2):229-50. 
15. Rvachew S. Longitudinal predictors of implicit phonological awareness skills. Am J Speech Lang Pathol. 2006; 15(2):165-76.

16. Rvachew S, Chiang PY, Evans N. Characteristics of speech errors produced by children with and without delayed phonological awareness skills. Lang Speech Hear Serv Schools; 2007; 38(1):60-71.

17. Cielo CA. Habilidades em consciência fonológica em crianças de 4 a 8 anos de idade. [tese] Porto Alegre (RS): Pontifica Universidade Católica; 2001. 18. Cielo CA. Avaliação de habilidades em consciência fonológica. J Bras Fonoaudiol. 2003; 4(16):163-74.

19. Cavalcante CA, Mendes MAM. A avaliação da consciência fonológica em crianças de primeira série alfabetizadas com metodologias diferentes. Rev CEFAC. 2003; 5(3):205-8.

20. Gillon GT. Follow-up study investigating the benefits of phonological awareness intervention for children with spoken language impairment. Int $\mathrm{J}$ Lang Commun Dis. 2002; 37(4):381-400.

21. Senechal M, Ouellette G, Young L. Testing the concurrent and predictive relations among articulation accuracy, speech perception, and phoneme awareness. J Exp Child Psychol. 2004; 89:242-69.

22. Sutherland D, Gillon GT. Assessment of phonological representations in children with speech impairment. Lang Speech Hear Serv Schools. 2005; 36(4):294-307.

23. Carroll JM, Snowling MJ. Language and phonological skills in children at high risk of reading difficulties. J Child Psychol Psychiatr. 2004; 45(3):631-40.

24. Gillon GT. Facilitating phoneme awareness development in 3- and 4-year old children with speech impairment. Lang Speech Hear Serv Schools. 2005; 36(4):308-24.

25. Rvachew S, Grawburg M. Correlates of phonological awareness in preschoolers with speech sound disorders. J Speech Lang Res. 2006; 49(1):74-87.
26. Laing SP, Espeland W. Low intensity phonological awareness training in a preschool classroom for children with communication impairments. J Commun Disord. 2005; 38(1):65-82.

27. Stackhouse J. Phonological awareness: connecting speech and literacy problems. In: Hodson BW, Edwards ML. Perspectives in applied phonology. Gaithersburg: Aspen; 1997. p.157-96.

28. Morales MV, Mota HB, Keske-Soares M. Habilidades em consciência fonológica em crianças com desvios fonológicos. J Bras Fonoaudiol. 2002; 3(10):72-5.

29. Morales MV, Mota HB, Keske-Soares M. Consciência fonológica: desempenho de crianças com e sem desvios fonológicos evolutivos. PróFono. 2002; 14(2):153-64.

30. Geudens A, Sandra D, van den Broeck W. Segmenting two-phoneme syllables: developmental differences in relation with early reading skills. Brain Lang. 2004; 90(1-3):338-52.

31. Betourne LS, Friel-Patti S. Phonological processing and oral language abilities in fourthgrade poor readers. J Commun Disord. 2003; 36(6):507-27.

32. Yavas M, Hernandorena CLM, Lamprecht RR. Avaliação fonológica da criança: reeducação e terapia. Porto Alegre: Artes Médicas; 1991. 148 p.

33. Holm A, Farrier F, Dodd B. Phonological awareness, reading accuracy and spelling ability of children with inconsistent phonological disorder. Int J Lang Commun Disord. 2008; 43(3):300-22.

34. Lewis BA, Freebairn LA, Taylor HG. Academic outcomes in children with histories of speech sound disorders. J Commun Disord. 2000; 33(1):11-30. 35. Mota HB, Melo Filha MGC, Lasch SS. A consciência fonológica e o desempenho na escrita sob ditado de crianças com desvio fonológico após realização de terapia fonoaudiológica. Rev CEFAC. 2007; 9(4):477-82.

DOI: 10.1590/S1516-18462009005000048

RECEBIDO EM: 29/07/2008

ACEITO EM: 17/03/2009

Endereço para correspondência:

Paula Marchetti

Rua Mal. Floriano Peixoto, 529/301

Santa Maria - RS

CEP: 97010-310

E-mail: paulamarchetti@farrapo.com.br paulam_fono@hotmail.com 